\title{
Impact of the alterations in the interstitial cells of Cajal on intestinal motility in post-infection irritable bowel syndrome
}

\author{
BO YANG ${ }^{1}, \mathrm{XU}-\mathrm{CHUN} \mathrm{ZHOU}^{1}$ and CHENG LAN ${ }^{2}$ \\ ${ }^{1}$ Department of Gastroenterology, The First Affiliated Hospital of Chongqing Medical University, Chongqing 400016; \\ ${ }^{2}$ Department of Gastroenterology, Hainan Provincial People's Hospital, Haikou, Hainan 400016, P.R. China
}

Received February 4, 2014; Accepted November 3, 2014

DOI: $10.3892 / \mathrm{mmr} .2014 .3039$

\begin{abstract}
The interstitial cells of Cajal (ICC) are basic components of gastrointestinal motility. However, changes in ICC and their role in post-infection irritable bowel syndrome (PI-IBS) remain to be elucidated. To observe the impact of alterations in the ICC on intestinal motility in a PI-IBS mouse model, female C57BLI6 mice were infected by the oral administration of 400 Trichinella spiralis larvae. The abdominal withdrawal reflex, intestine transportation time (ITT), grain numbers, Bristol scores, wet/dry weights and the percentage water content of the mice feces every $2 \mathrm{~h}$ were used to assess changes in the intestinal motor function. The intestines were excised and sectioned for pathological and histochemical examination. These intestines were also used to quantify the protein and mRNA expression of c-kit. The C57BL\6 mouse can act as a PI-IBS model at day 56 post-infection. Compared with the control mice, the ITT was shorter, the grain numbers, Bristol scores, wet weights and water contents of the mice feces were higher and the dry weights were unchanged in the PI-IBS mice. The protein and mRNA expression levels of c-kit were upregulated in the entire PI-IBS mouse intestines. Following immunohistochemical staining, the increased number of c-kit-positive cells were detected predominantly in the submucosa and myenteron. These results suggested that the alterations of the ICC resulted in the changes of the intestinal motility patterns in the PI-IBS mouse models induced by Trichinella spiralis infection, which may be the main mechanism underlying intestinal motility disorders in PI-IBS.
\end{abstract}

\section{Introduction}

Irritable bowel syndrome (IBS) is a highly prevalent functional gastrointestinal disorder characterized by abdominal pain and

Correspondence to: Professor Xu-Chun Zhou, Department of Gastroenterology, The First Affiliated Hospital of Chongqing Medical University, 1st Youyi Road, Chongqing 400016, P.R. China E-mail: chqxchzh@163.com

Key words: Trichinella spiralis, post-infection irritable bowel syndrome, interstitial cells of Cajal, motility disorder alterations in bowel habits (1). IBS caused by viral, bacterial and parasitic infection, observed in 3.7-36\% of patients, has been commonly referred to as PI-IBS (2). The pathophysiology of PI-IBS remains to be elucidated, however, low-grade inflammation and chronic alteration of the immune system at the molecular level have been shown to target the mucosal secretory function, smooth muscle and enteric nervous fibers (3-5). At present motility disorder is an established typical character in PI-IBS patients, however, alterations in the motility patterns in PI-IBS and the underlying mechanisms remain to be elucidated.

The interstitial cells of Cajal (ICC) are present throughout the gastrointestinal tract, from the esophagus to the anus, with three main functions, including acting as mechanoreceptors, transmitting enteric neuronal signals to the smooth muscle cells and placing slow waves and regulating their propagation (6). According to their location, the ICC are divided into the myenteric plexus (MP) ICC, intramuscular (IM) ICC, deep muscular plexus (DMP) ICC and the submucosa (SMP) ICC (6). All the subtypes are important components of gastrointestinal motility. Although certain studies have reported that ICC changed in PI-IBS patients and animal models $(7,8)$, the correlation between the patterns of gastrointestinal motor dysfunction and changes of the ICC remain to be elucidated. Therefore, the present study measured the feces and the c-kit protein in the different intestinal segments in PI-IBS model mice to elucidate the types of motility disorders and the association with changes in the ICC.

\section{Materials and methods}

Animals. The experimental procedure was approved by the Animal Welfare committee of Chongqing Medical University (Chongqing, China). Specific pathogen-free female C56BL/6 mice (4-6 weeks old) were purchased from the Animal Center of The Third Military Medical University (Chongqing, China). A total of 34 mice were randomly assigned to a control group $(n=17)$ and a model group $(n=17)$ and maintained in normal $12 \mathrm{~h}$ light/dark cycles in a regulated environment $\left(20-25^{\circ} \mathrm{C}\right)$. The study was approved by the ethics committee of the First Affiliated Hospital of Chongqing Medical University.

Trichinella spiralis infection. The infective muscle larvae were obtained from mice infected with Trichinella spiralis at 30 days. The infected mouse was sacrificed, skinned and 
eviscerated. The muscles containing the encysted larvae were minced and digested in $0.5 \%$ pepsin A (Biosharp, Hefei, China) and $0.5 \%$ hydrochloric acid for $16 \mathrm{~h}$ at $37^{\circ} \mathrm{C}$. The isolated infective larvae were washed several times with $0.85 \%$ sodium chloride and suspended in a balanced saline solution. The mice in the model group were infected by oral administration of 350-400 larvae in $0.2 \mathrm{ml}$ saline solution, whereas the control mice received only saline solution (9).

Sample collection and processing. In each group, three mice were humanely sacrificed (ether inhalation and cervical dislocation) at days 14, 28 and 56 post-infection (PI). The terminal ileum and proximal colon were sampled and flushed with physiological saline to remove the gut contents. A single sample of $1 \mathrm{~cm}$ in length from each intestinal tissue was fixed overnight in $4 \%$ paraformaldehyde and embedded in paraffin for immunochemical and hematoxylin and eosin (H\&E) analysis. The intestine tissues of the remaining mice were removed and preserved in liquid nitrogen immediately for subsequent mRNA and protein extraction.

Abdominal withdrawal reflex (AWR). The behavioral responses to colorectal distention (CRD) were assessed at day 56 PI by measuring the AWR (10). Briefly, the distention was applied using a balloon ( $2 \mathrm{~mm}$ external diameter, $10 \mathrm{~cm}$ length), which was inserted rectally into the descending colon of the mildly sedated mice, inserted with ether inhalation and fixed at the base of the tail. The mice were then housed in glass cubicles $(20 \times 8 \times 8 \mathrm{~cm})$ and were left to wake and acclimate for $1 \mathrm{~h}$. The balloon was distended with $0.25 \mathrm{ml}, 0.35 \mathrm{ml}, 0.5 \mathrm{ml}$ and $0.65 \mathrm{ml}$ water for $20 \mathrm{sec}$. Each distention was repeated three times with $30 \mathrm{sec}$ intervals and the balloon was then deflated and withdrawn following assessment of the AWR. The AWR score was assigned as follows: 0, no behavioral response to CRD; 1 , brief head movement followed by immobility; 2, contraction of abdominal muscles; 3 , lifting of abdomen and 4 , body arching and lifting of pelvic structures (11).

Measurement of intestinal motility. All the mice were orally administrated with $0.3 \mathrm{ml}$ activated carbon suspension and the time until production of the first black fecal pellets was recorded to evaluate ITT. The fecal pellets were collected every $15 \mathrm{~min}$ for $8 \mathrm{~h}$ until the color of feces returned to normal. The collected stool was weighed and desiccated every $2 \mathrm{~h}$. This was performed by measuring the stool weight prior to and following oven drying $\left(24 \mathrm{~h}\right.$ at $70^{\circ} \mathrm{C}$ in the presence of desiccant) and the water content percentage was calculated. The grain numbers, wet weights, percentage liquid content, dry weights and Bristol scores were then compared with each other. The criteria for stool scoring were established as follows (8): 1, normal stool; 2, soft and poorly formed stool 3 , watery stool.

Immunohistochemical staining. The paraffin-embedded tissues were cut into $5 \mu \mathrm{m}$-thick sections. To deparaffinize the sections, they were immersed in xylene at $56^{\circ} \mathrm{C}$ twice for 20 min and hydrated with ethanol (twice with $100 \%$, once with $95 \%$ and once with $75 \%$ ethanol) for $5 \mathrm{~min}$. The sections were then pretreated with $3 \%$ hydrogen peroxide for $20 \mathrm{~min}$ at $37^{\circ} \mathrm{C}$ and antigen retrieval was performed by boiling the sections in citrate buffer (0.01 M; pH 6.0) for $20 \mathrm{~min}$. Following cooling at room temperature for $1 \mathrm{~h}$, the specimens were treated with $5 \%$ bovine serum albumin for $30 \mathrm{~min}$ at $37^{\circ} \mathrm{C}$ followed by overnight incubation with 1:200 diluted rabbit anti-mouse c-kit polyclonal antibody (Boster Biotechnology, Ltd., Wuhan, China) at $4^{\circ} \mathrm{C}$. Following washing in phosphate-buffered saline, the slides were incubated for $60 \mathrm{~min}$ at $37^{\circ} \mathrm{C}$ with the corresponding secondary biotinylated goat anti-rabbit antibody (Boster Biotechnology, Ltd.) at a 1:300 dilution. Following washing, the slides were incubated with Diaminobenzidine chromogen (Zsbio, Beijing China) for 5 min. A nuclei counterstain was performed using Mayer's hematoxylin (Boster Biotechnology, Ltd., Wuhan, China). The slides were then washed with water and immersed in 75, 85, 90 and $100 \%$ ethanol and $100 \%$ xylene. The sealed slides were recorded digitally using a Leica Microsystem (DM6000B, Leica, Mannheim, Germany). The immunohistochemical analysis was scored as staining intensity and the proportion of positive cells (12). The scale of staining intensity was as follows: 0 , not detected; 1 , minimal; 2, mild; 3 , moderate and 4, marked. The proportion of positive cells scale was: 0 , no staining, 1 , c-kit-positive cells in $<1 \%$ population; 2 , c-kit-positive cells in $1-10 \%$ population; 3 , c-kit-positive cells in $10-50 \%$ and 4 , c-kit-positive cells in $>50 \%$ population.

Reverse transcription quantitative polymerase chain reaction (RT-qPCR) mRNA assay. The total RNA in the intestinal mucosa was extracted using TRIzol solution (Takara Bio, Inc., Shiga, Japan). The gene expression of c-kit was assayed by RT-qPCR. The $\beta$-actin mRNA level was determined as an internal reference and their levels of expression were quantitated by optical densitometry following electrophoresis on an agarose gel. The primers were designed based on the following complementary DNA sequencs: $\beta$-actin (470 bp), forward 5'-AGGCTGTGCTGTCCCTGTATG-3' and reverse 5'-GAGGTCTTTACGGATGTCAACG-3' and c-kit (214 bp), forward 5'-CGACGCAACTTCCTTATGAT-3' and reverse 5'-AGGACCTTCAGTTCCGACAT-3'. The RT was performed at $37^{\circ} \mathrm{C}$ for $15 \mathrm{~min}$ and $85^{\circ} \mathrm{C}$ for $5 \mathrm{sec}$. The PCR cycling condition was 36 cycles at $94^{\circ} \mathrm{C}$ for $30 \mathrm{sec}, 59^{\circ} \mathrm{C}$ ( $\beta$-actin) or $56^{\circ} \mathrm{C}$ (c-kit) for $30 \mathrm{sec}$ and $72^{\circ} \mathrm{C}$ for $35 \mathrm{sec}$. The PCR end products were electrophoresed on $4 \%$ agarose gel and stained with ethidium bromide. The gray values of the bands were calculated using Quantity One software (Bio-Rad). The relative mRNA expression levels of target genes were normalized to the corresponding internal standard.

Western blotting for protein assay. The frozen sample was fractured using an ultrasonic disrupter (HD3100, Bandelin Electronic, Berlin, Germany), suspended in radioimmunoprecipitation buffer (Takara Bio Inc.) for $20 \mathrm{~min}$ and the protein levels in the supernatants were obtained following centrifugation at $12,000 \mathrm{x}$ g for $20 \mathrm{~min}$ and quantified using a bicinchoninic acid protein assay kit (Beyotime Institute of Biotechnology, Shanghai, China). Aliquots (60 $\mu \mathrm{g})$ of the protein were subjected to electrophorese on a polyacrylamide gel for the c-kit protein. The primary antibodies were goat anti-mouse c-kit polyclonal antibody (Boster Biotechnology, Ltd.) at a dilution of 1:500 and goat anti-mouse $\beta$-actin polyclonal antibody (Boster Biotechnology, Ltd.) at a dilution of 
Table I. Abdominal withdrawal reflex scores for colon distention of mice in the model and control groups.

\begin{tabular}{llcccc}
\hline Group & $\mathrm{n}$ & $0.25 \mathrm{ml}$ & $0.35 \mathrm{ml}$ & $0.5 \mathrm{ml}$ & $0.65 \mathrm{ml}$ \\
\hline Model & 8 & $0.50 \pm 0.25$ & $2.42 \pm 0.24^{\mathrm{a}}$ & $3.54 \pm 0.31^{\mathrm{a}}$ & $3.88 \pm 0.35$ \\
Control & 8 & $0.33 \pm 0.31$ & $1.83 \pm 0.44$ & $2.92 \pm 0.43$ & $3.75 \pm 0.46$ \\
\hline
\end{tabular}

Data are presented as the mean \pm standard deviation. ${ }^{a} \mathrm{P}<0.0,1$ compared with the control group.

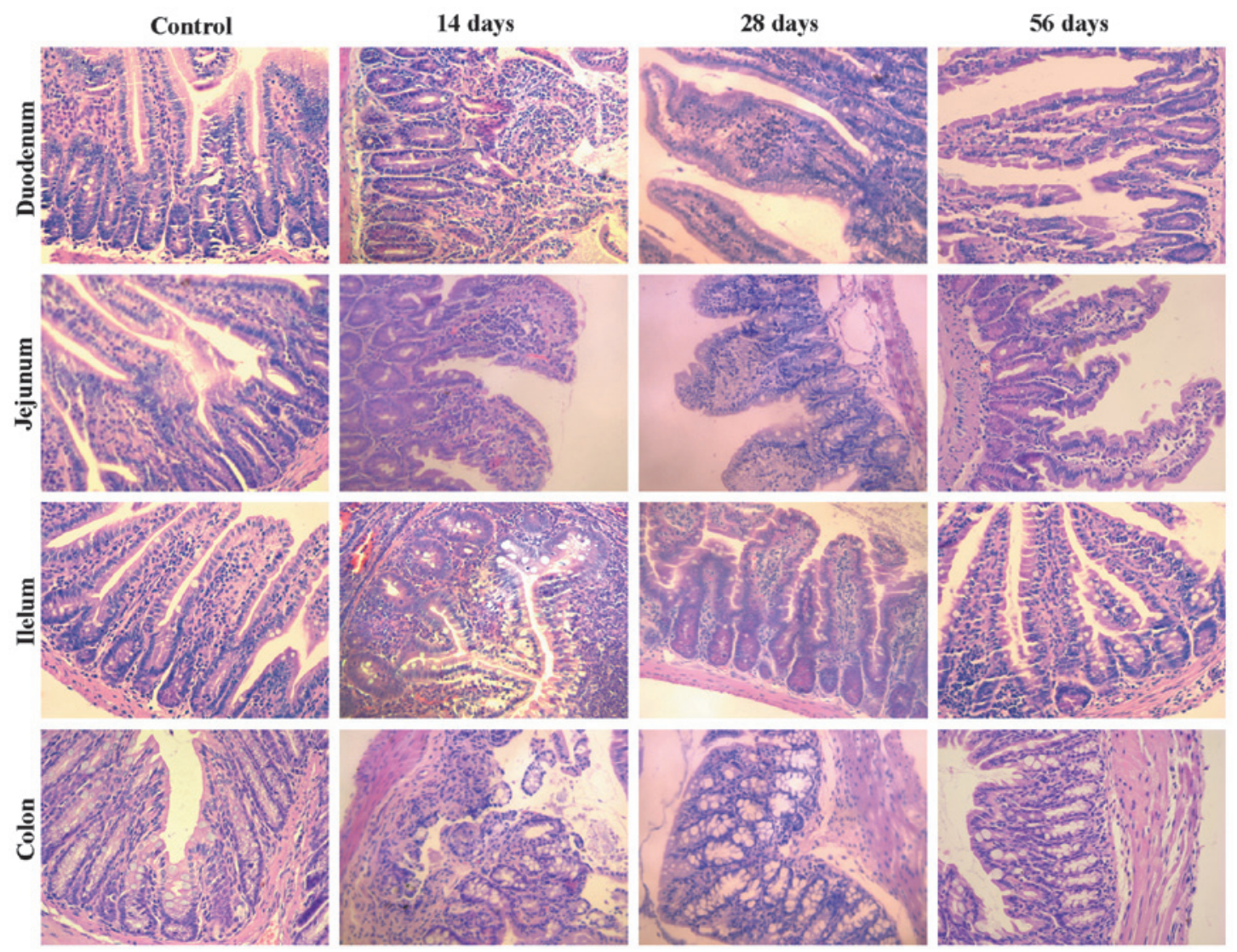

Figure 1. Histological analysis of the intestinal tissues. Sections of duodenum, jejunum, ileum and colon from the control and model mice were stained with hematoxylin and eosin on different days (original magnification, $x 200 ; n=3$ ).

1:1,000 The $\beta$-actin protein was used as an internal standard. The signal was detected using an enhanced chemiluminescence detection system (Bio-Rad). The densities of the bands were assessed using Quantity One software (Bio-Rad). The relative protein levels of the target protein were obtained by correction with the corresponding internal standard.

Statistical analysis. Statistical analysis was performed using SPSS 19.0 software (IBM SPSS, Armonk, NY, USA). Data are expressed as the mean \pm standard deviation. The independent sample t-test was used to compare the results between the two groups. $\mathrm{P}<0.05$ was considered to indicate a statistically significant difference.

\section{Results}

Pathological examination. H\&E staining (Fig. 1) revealed a marked infiltration by neutrophils in the lamina propria and interstitial edema on day 14 PI. Infiltration and edema gradually reduced between days 14 and 28 PI. At 56 days PI, no obvious inflammatory infiltrate was observed and from this day, the mice were deemed suitable as PI-IBS model mice.

AWR. At distention volumes of 0.35 and $0.5 \mathrm{ml}$, the AWR scores in the model mice were higher compared with those in the controls, which indicated that the visceral sensitivity to colorectal distension was increased in the model mice. No significant differences were observed at volumes of 0.25 or $0.65 \mathrm{ml}$ (Table I).

Measurement of intestinal motility. The ITT of the PI-IBS group was markedly shorter compared with the control group. Compared with those of the control group, the grain numbers, wet weights, Bristol scores and percentage liquid contents were significantly higher, however, the dry weights were not different between the two groups (Fig. 2). 

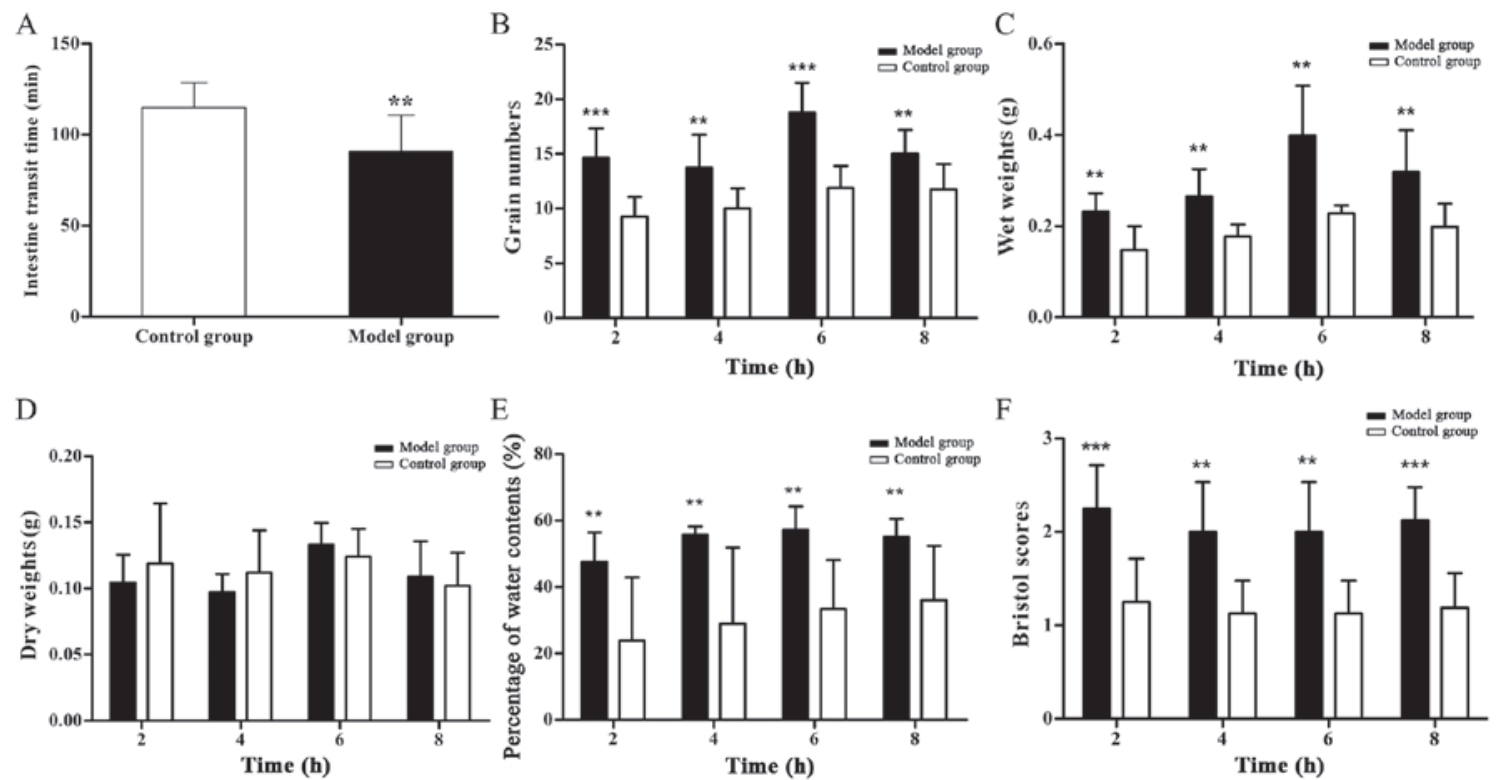

Figure 2. Comparison of intestinal motility between the model and control groups. (A) Intestinal transmit time; (B) Feces grain number; (C) Wet weight of feces; (D) Dry weight of feces; (E) Percentage water content; (F) Bristol score of feces. Error bars represent the mean \pm standard deviation. $n=8$. "* $\mathrm{P}<0.01$ and ${ }^{* * *} \mathrm{P}<0.001$ compared with the control group.
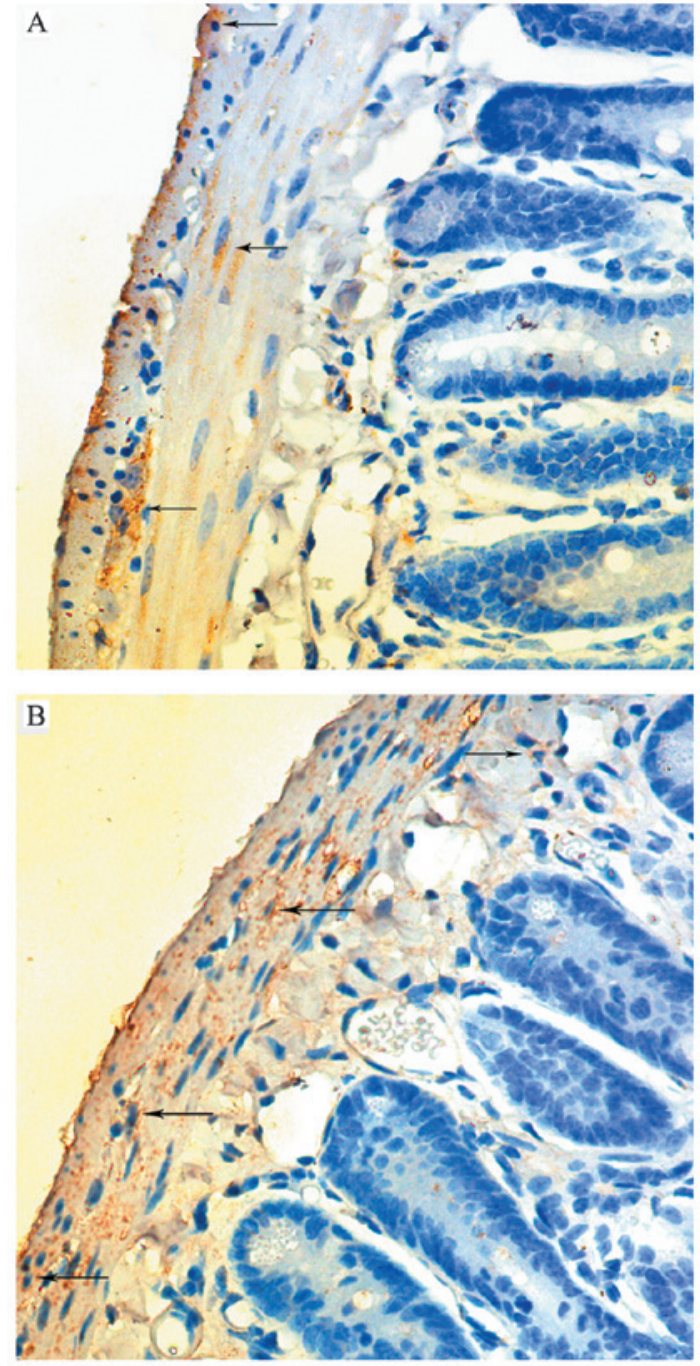

Figure 3. Immunochemical staining of the c-kit protein. Black arrows indicate c-kit-positive cell; (A) Control group; (B) model group (original magnification, $\mathrm{x} 400 ; \mathrm{n}=3)$.

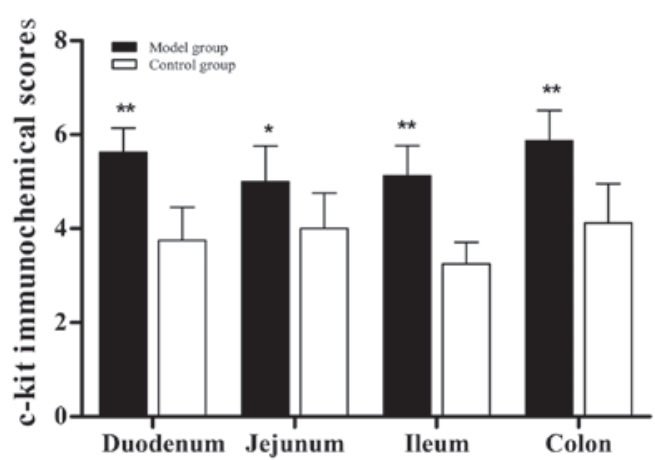

Figure 4. Comparison of the c-kit immunochemical scores between the model and control group. Error bars represent the mean \pm standard deviation. $\mathrm{n}=5 .{ }^{*} \mathrm{P}<0.05$, and ${ }^{* *} \mathrm{P}<0.01$ compared with the control group.

Immunohistochemical staining. The immunolabeling revealed that the c-kit signals were detected predominantly in the submucosa and myenteron (Fig. 3). The staining scores of the entire intestines in the model group were notably higher compared with those of the control group (Fig. 4).

RT-PCR and western blotting assays. The results of the RT-PCR and western blotting assays demonstrated that the mRNA and protein levels of c-kit were significantly higher in the duodenum, jejunum, ileum and colon of the PI-IBS mice compared with the control mice (Figs. 5 and 6).

\section{Discussion}

PI-IBS is defined as the acute onset of IBS symptoms (meeting Rome III criteria) that develop when an individual, who has not previously met the Rome criteria, experiences a gastrointestinal infection with two or more of the following characteristics: fever, vomiting, diarrhea or a stool culture positive for an infectious agent (13). The Rome III criteria 

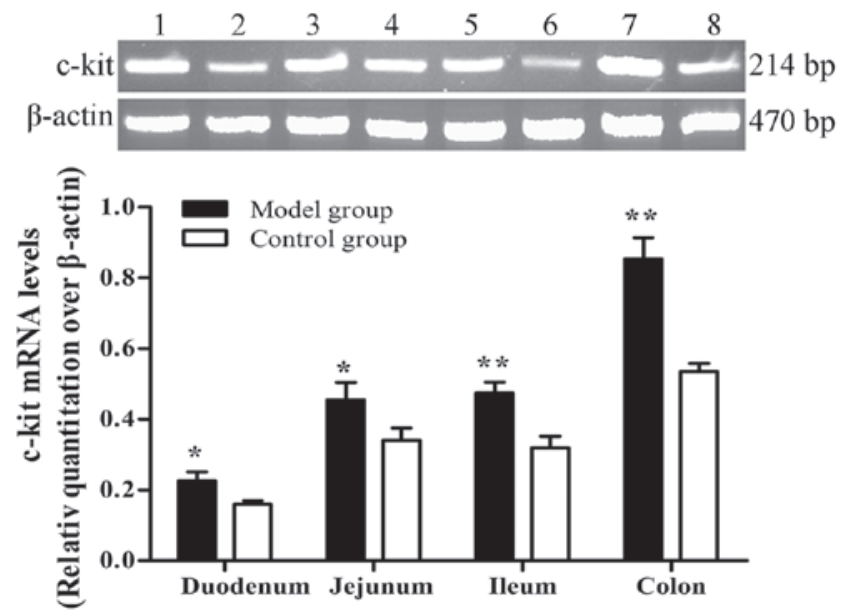

Figure 5. Relative mRNA levels of c-kit in the different intestinal segments. Reverse transcription polymerase chain reaction was performed. Lanes 1, 3, 5 and 7 represent the duodenum, jejunum, ileum and colon of the model mice, respectively; 2, 4, 6 and 8 represent the duodenum, jejunum, ileum and colon of the control mice, respectively. Error bars represent the mean \pm standard deviation. $\mathrm{n}=8$. ${ }^{*} \mathrm{P}<0.05$, and ${ }^{* *} \mathrm{P}<0.01$ compared with the control group.

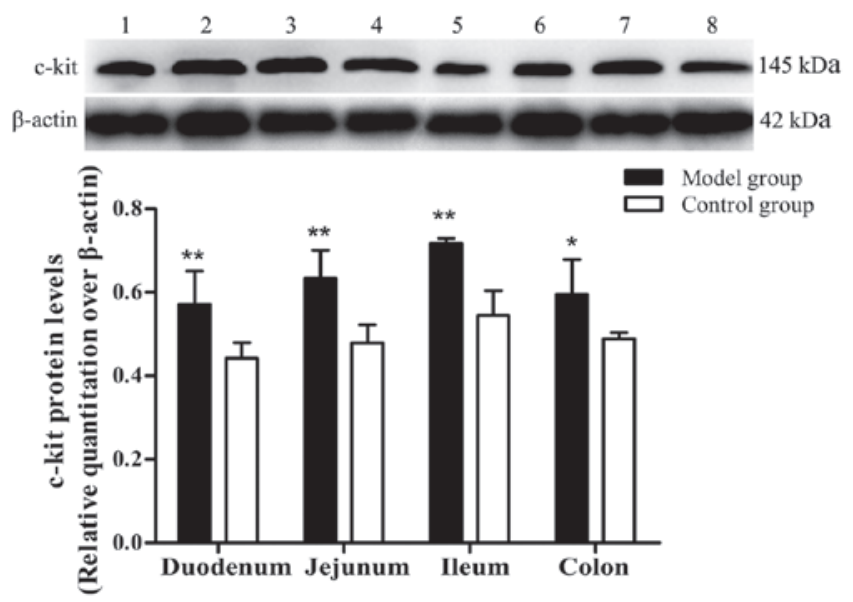

Figure 6. Relative protein levels of c-kit in the different intestinal segments. Western blot analysis was performed. Lanes 1, 2, 3 and 4 represent the duodenum, jejunum, ileum and colon of the model mice, respectively; 5, 6, 7 and 8 represent the duodenum, jejunum, ileum and colon of the control mice, respectively. Error bars represent the mean \pm standard deviation. $n=8$. ${ }^{*} \mathrm{P}<0.05$ and ${ }^{* *} \mathrm{P}<0.01$ compared with the control group.

are as follows: Recurrent abdominal pain or discomfort should be present for at least three days per month over the past three months and be associated with $\geq 2$ of: involvement with defecation, onset associated with a change in frequency of stool, onset associated with a change in form of stool. These criteria must be fulfilled over the past three months with symptom onset occurring at least six months previously. Although the mechanism remains to be elucidated, visceral hypersensitivity and intestinal motor dysfunction are reported to be involved (14). The present study used a previously described method to establish a PI-IBS mouse model (15). Through the dynamic observation of intestinal histology and AWR scores, the infected mice were used as PI-IBS mice when the intestine returned to normal. According to the results of intestinal motility, the present study suggested that the frequency and rhythm of intestinal peristalsis altered in the model mice. The frequency and rhythm of bowel movement is completed by ICC, smooth muscle cells and the enteric nervous system in combination and ICC provides a pacemaker signal for coordinated motility patterns. As ICC is important in bowel movement (16), the present study hypothesized that ICC were changed in the PI-IBS model mice infected by Trichinella spiralis. To confirm this hypothesis, the c-kit protein was used to determine the number and function of the intestinal ICC, which is an important biological symbol and is expressed in the ICC of the intestinal muscular layer and lamina propria (6). The mucosal inflammation of the gut induced by Trichinella spiralis infection resulted in loss of ICC function due to structural injury and loss of c-kit positivity (17). In inflammation subsidence, the rough endoplasmic reticulum and Golgi apparatus of the injured ICC are required to synthesize proteins, including c-kit, to form a new plasma membrane and to recover structure and function (17). The present study found that the protein and mRNA expression of c-kit were significantly higher in the PI-IBS mice compared with the control mice. Overexpressed c-kit is required for development and maintenance of ICC, was also necessary for development of coordinated motility patterns and for the survival of ICC $(18,19)$. In several diseases, an association between macrophages and ICC injury has been identified $(20,21)$. However, in vivo, 5-hydroxytryptamine (5-HT) released from macrophages and an increase in PI-IBS can combine with 5-HT2B receptors, which are expressed on the plasma membrane of ICC and this promotes proliferation of the ICC $(22,23)$. The present study found that the c-kit-positive cells increased in the intestine of the PI-IBS mice.

On resolution of submucosal and myenteric inflammation, the network of ICC, particularly that involved in connecting ICC to each other and to smooth muscle cells, return to a normal physiological state, whereas the increased ICC in PI-IBS mice may induce intestinal motor disturbances similar to that induced by inflammation $(24,25)$. The present study observed that the signals of c-kit were predominantly detected in the submucosa and myenteron, where the ICC mainly pace slow waves (26). Increased ICC has the potential to place more slow waves and this alteration can accelerate the intestinal muscular contraction and peristaltic propagation (27). In addition, increased cholecystokinin in PI-IBS can bind to cholecystokinin A receptors expressed on ICC and promote gastrointestinal emptying $(28,29)$. Furthermore, an increase in the number of IM-ICC can shorten the intervals between the migratory motor complex (MMC) cycles and decrease the bowel transmitting time (30). These mechanisms mean that the reduced time of the whole gastrointestinal transmitting was closely associated with the ICC changes.

The small intestine is the primary site of nutrient absorption. As the frequency and rhythm of bowel movement increase, the higher osmotic pressure of food residue entering the colon is not conducive to water absorption. However, the reduced contact time between food waste and intestinal wall results in a markedly higher water content and higher Bristol scores of the feces (31).

In the present study, the observed increase in feces grains and similar dry weights between the two groups indicated 
that the MMC frequency increased and the underlying mechanisms may be associated with an increase in the number of slow waves and short time intervals in the MMC cycles (30). However, an increase in the number of IM-ICC leads to increased nitric oxide transmission and subsequently decreased MMC frequency (15). Whether the association between ICC and nitric oxide transmission was abnormal in PI-IBS requires further investigation.

In conclusion, a PI-IBS model was successfully established in the present study using C57BL\6 mice induced by Trichinella spiralis. Alterations in the ICC numbers and c-kit protein were closely associated with changes in the intestinal motor patterns in PI-IBS. However, further studies are required to confirm the association between the ICC and intestinal motility disorders in PI-IBS.

\section{Acknowledgements}

This study was supported by the National Natural Science Foundation of China (grant no. 81160057). The authors would like to thank Professor Bao-Quan Fu (Chinese Academy of Agricultural Sciences, Beijing, China) for offering Trichinella spiralis and Professor Yu Li and Mr. Bing Liu (Department of Anatomic Pathology, Chongqing Medical University) for their technical assistance.

\section{References}

1. Choung RS and Locke III GR: Epidemiology of IBS. Gastroenterol Clin North Am 40: 1-10, 2011.

2. Longstreth GF, Thompson WG, Chey WD, Houghton LA, Mearin F and Spiller RC: Functional bowel disorders. Gastroenterology 130: 1480-1491, 2006.

3. Spiller R and Garsed K: Postinfectious irritable bowel syndrome. Gastroenterology 136: 1979-1988, 2009.

4. Elsenbruch S, Holtmann G, Oezcan D, Lysson A, Janssen O, Goebel MU and Schedlowski M: Are there alterations of neuroendocrine and cellular immune responses to nutrients in women with irritable bowel syndrome[quest]. Am J Gastroenterol 99: 703-710, 2004

5. Liebregts T, Adam B, Bredack C, Röth A, Heinzel S, Lester S, Downie-Doyle S, Smith E, Drew P, Talley NJ and Holtmann G: Immune activation in patients with irritable bowel syndrome. Gastroenterology 132: 913-920, 2007.

6. Sarna SK: Are interstitial cells of Cajal plurifunction cells in the gut? Am J Physiol Gastrointest Liver Physiol 294: 11, 2008.

7. Jee SR, Morales W, Low K, Chang C, Zhu A, Pokkunuri V, Chatterjee S, Soffer E, Conklin JL and Pimentel M: ICC density predicts bacterial overgrowth in a rat model of post-infectious IBS. World J Gastroenterol 16: 3680, 2010.

8. Pokkunuri V, Pimentel M, Morales W, Jee SR, Alpern J, Weitsman S, Marsh Z, Low K, Hwang L, Khoshini R, et al: Role of Cytolethal Distending Toxin in Altered Stool Form and Bowel Phenotypes in a Rat Model of Post-infectious Irritable Bowel Syndrome. J Neurogastroenterol Motil 18: 434-442, 2012.

9. Wheatcroft J, Wakelin D, Smith A, Mahoney CR, Mawe G and Spiller R: Enterochromaffin cell hyperplasia and decreased serotonin transporter in a mouse model of postinfectious bowel dysfunction. Neurogastroenterol Motil 17: 863-870, 2005.

10. Distrutti E, Sediari L, Mencarelli A, Renga B, Orlandi S, Antonelli E, Roviezzo F, Morelli A, Cirino G, Wallace JL and Fiorucci S: Evidence that hydrogen sulfide exerts antinociceptive effects in the gastrointestinal tract by activating KATP channels. J Pharmacol Exp Ther 316: 325-335, 2006.

11. Al-Chaer ED, Kawasaki M and Pasricha PJ: A new model of chronic visceral hypersensitivity in adult rats induced by colon irritation during postnatal development. Gastroenterology 119: 1276-1285, 2000.
12. Zagzag D, Zhong H, Scalzitti JM, Laughner E, Simons JW and Semenza GL: Expression of hypoxia-inducible factor $1 \alpha$ in brain tumors: association with angiogenesis, invasion and progression. Cancer 88: 2606-2618, 2000 .

13. Ghoshal UC and Ranjan P: Post-infectious irritable bowel syndrome: the past, the present and the future. J Gastroenterol Hepatol 26: 94-101, 2011.

14. Spiller R and Garsed K: Postinfectious irritable bowel syndrome. Gastroenterology 136: 1979-1988, 2009

15. Bercik P, Wang L, Verdu EF, Mao YK, Blennerhassett P, Khan WI, Kean I, Tougas G and Collins SM: Visceral hyperalgesia and intestinal dysmotility in a mouse model of postinfective gut dysfunction. Gastroenterology 127: 179-187, 2004.

16. Eshraghian A and Eshraghian H: Interstitial cells of Cajal: a novel hypothesis for the pathophysiology of irritable bowel syndrome. Can J Gastroenterol 25: 277-279, 2011.

17. Wang XY, Vannucchi MG, Nieuwmeyer F, Ye J, Faussone-Pellegrini MS and Huizinga JD: Changes in interstitial cells of Cajal at the deep muscular plexus are associated with loss of Distention-Induced Burst-Type Muscle Activity in Mice Infected by Trichinella spiralis. Am J Pathol 167: 437-453, 2005.

18. Rich A, Gordon S, Brown C, Gibbons SJ, Schaefer K, Hennig G and Farrugia G: Kit signaling is required for development of coordinated motility patterns in zebrafish gastrointestinal tract. Zebrafish 10: 154-160, 2013.

19. Ghaith O, El-Halabi M, Hashash JG and Sharara AI: Investigational agents for the irritable bowel syndrome. Expert Opin Investig Drugs 19: 1161-1178, 2010

20. Rumessen JJ: Ultrastructure of interstitial cells of Cajal at the colonic submuscular border in patients with ulcerative colitis. Gastroenterology 111: 1447-1455, 1996.

21. Suzuki T, Won K-J, Horiguchi K, Kinoshita K, Hori M, Torihashi S, Momotani E, Itoh K, Hirayama K, Ward SM, Sanders KM and Ozaki H: Muscularis inflammation and the loss of interstitial cells of Cajal in the endothelin ETB receptor null rat. Am J Physiol Gastrointest Liver Physiol 287: 638-646, 2004.

22. Chun L and Bai Y: Experimental research on modifying liver and spleen decoction for diarrhea-predominant IBD. J Nanjing Univ Trad Med 2: 019, 2011.

23. Wouters MM, Roeder JL, Tharayil VS, Stanich JE, Strege PR, Lei S, Bardsley MR, Ordog T, Gibbons SJ and Farrugia G: Protein kinase $\mathrm{C} \gamma$ mediates regulation of proliferation by the serotonin 5-hydroxytryptamine receptor 2B. J Biol Chem 284: 21177-21184, 2009.

24. Der T, Bercik P, Donnelly G, Jackson T, Berezin I, Collins SM and Huizinga JD: Interstitial cells of cajal and inflammation-induced motor dysfunction in the mouse small intestine. Gastroenterology 119: 1590-1599, 2000.

25. Bettolli M, De Carli C, Cornejo PD, Jolin DK, Wang XY, Huizinga J, Krantis A, Rubin S and Staines WA: Interstitial cell of Cajal loss correlates with the degree of inflammation in the human appendix and reverses after inflammation. J Pediatr Surg 47: 1891-1899, 2012.

26. Ward SM, Harney SC, Bayguinov JR, McLaren GJ and Sanders KM: Development of electrical rhythmicity in the murine gastrointestinal tract is specifically encoded in the tunica muscularis. J Physiol 505: 241-258, 1997.

27. Eshraghian A and Eshraghian H: Interstitial cells of Cajal: a novel hypothesis for the pathophysiology of irritable bowel syndrome. Can J Gastroenterol 25: 277-279, 2011.

28. Patterson L, Zheng H, Ward S and Berthoud HR: Immunohistochemical identification of cholecystokinin A receptors on interstitial cells of Cajal, smooth muscle, and enteric neurons in rat pylorus. Cell Tissue Res 305: 11-23, 2001.

29. Dizdar V, Spiller R, Singh G, Hanevik K, Gilja OH, El-Salhy M and Hausken T: Relative importance of abnormalities of CCK and 5-HT (serotonin) in Giardia-induced post-infectious irritable bowel syndrome and functional dyspepsia. Aliment Pharmacol Ther 31: 883-891, 2010.

30. Powell AK and Bywater RA: Murine intestinal migrating motor complexes: longitudinal components. Neurogastroenterol Motil 15: 245-256, 2003.

31. Surawicz C: Mechanisms of diarrhea. Curr Gastroenterol Rep 12: 236-241, 2010. 